\title{
SPATIAL AND STRUCTURAL ASPECTS OF AN ADAPTABLE BUILDING
}

\author{
Eunike Kristi Julistiono ${ }^{1 *}$, Nikolas Hosana ${ }^{2}$, Fida Liemansetyo ${ }^{2}$, Irene Felicia Wijaya ${ }^{2}$ \\ ${ }^{1}$ Department of Architecture, Petra Christian University, Siwalankerto 121-131, Surabaya, INDONESIA \\ ${ }^{2}$ Students of Architecture Department, Petra Christian University, Siwalankerto 121-131, Surabaya, INDONESIA \\ *Corresponding author; Email: kristi@petra.ac.id
}

\begin{abstract}
At the moment, in the era of energy crisis and climate change, designing a sustainable building is mandatory to minimize building construction and operational impacts, and to ensure the sustainability of the ecology. Prolong the life span of the building is one important strategy to achieve a sustainable building. Longer life span can be achieved if the building has continual adaptability towards changes of needs along its life span. This paper presents the design of an adaptable building with a modular, movable, and knock-down construction. In here, two important aspects in the creation of an adaptable building - the spatial and structural aspects, are considered. The result is a sustainable building with flexible and fluctuating space which is able to adapt to different functional requirements.
\end{abstract}

Keywords: Adaptable; fluctuating space; modular; knock-down.

\section{INTRODUCTION}

Over the past two decades, the world has been facing global warming and climate change due to over consumption of resources and energy. Massive use of fossil fuel, wasteful energy used for heating, cooling, lighting, and ventilating, deforestation, and urbanization have caused enormous greenhouse gas emission. In effect, ever since the beginning of industrial revolution, the concentration of greenhouse gasses in the atmosphere has increased more than $30 \%$ (Smith, 2007). It has brought enormous impact towards sustainability of the earth, includes higher temperature and more heat waves, more drought, wild fire, and natural disasters, less snow and ice, rise of sea level, damaged corals and extinction of species (Dechert, 2015).

Facing the crisis that the world is facing at the moment, sustainable development which satisfying the needs of the present without compromising the needs of the future generation is necessity. Construction industry is responsible for $50 \%$ of resources use, $40 \%$ of generated energy, $16 \%$ of global water use, $45 \%$ of greenhouse gas emission (Akmal, 2007). Thus, recognizing that construction industry is the least sustainable industry, it is important to design and produce a sustainable architecture.

Sustainable architecture is designed to minimize energy and resources use, minimize its environmental impact, and increasing the living quality of its occupants, while remain harmony with its surrounding environment, climate, culture, and mantain the ecology sustainability (AIJ, 2005). Sustainable architecture implements cradle to grave philosophy, which means that in designing a sustainable building, each phase of building life cycle should be taken into consideration, not only design and construction phases, but also operational/occupancy phase, and even post-occupancy phase. It also involves anticipating the needs of modification and maintenance along building occupancy period. Therefore, building life cycle management includes continual adaptation to changing needs and renovation to repair deterioration of building construction.

Prolong the building and material's life span is essential in achieving sustainable building (Julistiono, 2011). Increasing the life span of a building or increasing the period of use of a material means delaying the need to build a new construction or to create a new material. Hence, it minimizes resources and energy use, and minimizes environmental impact. Reduce, reuse, recycle, refurbish (4Rs) is known as some strategies to achieve sustainable development. Reduce means reducing resources and energy use in construction, operation, and maintenance of a building. Reuse of a material/construction component with similar application into new construction and recycle the material at the end of its life to produce a new material are both aiming to prolong the life span of a material. While refurbish means adapting a building to be able to accommodate another function at the end of its life cycle. The last strategy shows that adaptability is significant in sustainable development.

Adaptability is an important strategy in designing a sustainable building. One of the problems which is likely have to be encountered in creating a sustainable building is the changing in social and economic condition over building life span which usually causes changing of building function and occupancy needs. For example, a company may build an office to accommodate its activities. However, over 50 years, the company may grow bigger and need more spaces. If the initial office is designed without anticipating the changing needs over time, the office may need to be 
renovated or dismantled sooner than its actual life expectancy. Croxton said (Schmidt III et al, 2010b), "If a building doesn't support change and reuse, you have only an illusion of sustainability." To design a sustainable building, and ensure that it will operate in a sustainable way, the building has to be designed with certain adaptability. It must be able to adapt to changing of needs over its life span.

An adaptable building is designed as an unfinished construction, intended to evolve along its life span (Schmidt III et al, 2010b). Designing an adaptable building means allowing various spatial and functional configurations accommodated by the building design, through utilizing building technology, so that the changes will not disturb the building structure and activities (Kronenburg, 2007). Among many aspects considered in the creation of an adaptable building (Nakib, 2010), there are two main aspects considered in this paper; spatial and structural properties of the building. To adapt to different needs, architectural space should be designed to be flexible yet suitable to the functional requirements. Thus, the structural system should be able to accommodate different lay-out configurations.

This paper discusses the process of designing an adaptable building to support sustainable development. The objective is to be an example of how to create a sustainable adaptable building, especially in spatial and structural characteristics. To show that to create an adaptable building, certain design of structure and construction is required; a modular, movable, and even knock-down construction. First, the design methodology is explained, followed by the literature review regarding an adaptable building and adaptability. Then, the case study taken in the design process is described, followed by the design result and the discussion.

\section{METHODOLOGY}

In designing an adaptable building, several steps are involved; literature study, case study exploration, and schematic design process.

- Literature study

Literature study is performed in order to learn about adaptability and the concept of adaptable building. It is needed to understand the necessity of adaptable building, what is its characteristics, how to create an adaptable building, along with the principles and techniques required in the creation process, as well as examples of the implementation.

- Case study exploration

To simplify the design process, a case study is chosen as an inspiration to be implemented in the design. The case study taken is a real project, designed with natural analogy approach (by realizing that natural analogy is often used in creating a sustainable architectural structure), and known to have some sustainable features.

- Schematic design process

The schematic design process is preceded by design requirements selection. Gallery was chosen as the function to be accommodated in the design. Once the program was decided, the design process was started. The design process has incorporated several techniques usually implemented in the creation of sustainable building, especially in producing the structural solution and the construction details.

\section{ADAPTABLE BUILDING}

To achieve a sustainable architecture, adaptability is the solution in responding changes. Everything in the world constantly changes, including economic, social, and cultural condition, and indirectly affects building development. Society has tendency to evolve, for the purpose of better livings. In consequence, to accommodate this changes in needs, architecture has to change. The most common way to respond to change is by demolishing and rebuilding. However, this method is highly inefficient and not sustainable; it means wasting of building resources, ecologically damaging, and inefficient in terms of placing the facility out of use for a period of time. Facing these issues, the idea of adaptable building is an ideal solution. By implementing adaptable principles, building remains in use longer, fits its purpose better, accommodates variation of user's activities, and thus economically and ecologically more viable (Kronenburg, 2007).

Adaptability is an ability to adjust to change, whether it is a change of building functions, users, or systems without significant disruption of ongoing activities and environment. The main idea is exploring the possibility of a building to continuously evolve throughout its life span in response to changing of users/society's needs (Schmidt III et al, 2010b). Adaptable building should be resilient from changes throughout its lifetime, including changes in social, economic, and environmental conditions. Socially, an adaptable building provides satisfaction for individual/common needs, including giving space for user's intervention. Economically, an adaptable building fulfils its function more efficiently, prolongs its service, reduces material consumption through time, and is responsive to technological innovations. Environmentally, it decreases energy consumption and ensures minimum environment impact (Nakib, 
2010). There are four key characteristics in adaptable building; ability to change, stay proper for purpose, maximizing its value, and respond readily and from time to time (Schmidt III et al, 2010b). Therefore, adaptability can be defined as building ability to stay fit, while readily responding to changes, in maximizing its value.

With many different approaches in creating an adaptable building, there are two major strategies that has often been applied up until now (Kronenburg, 2007):

- Open building

A common implementation of adaptable building concept is known as 'open building'. An open building has loose fit elements with the purpose of responding changes. Open building principle is a strategy that allows multi-use space to accommodate various functions. To apply this principle, during design process, reference of future changes should be included but not to restrict flexibility by user's intervention.

- Fluctuating space

This principle has been developed based on the disadvantage of an open building principle. Multiuse space in open building principle often causes the space quality becomes ordinary and unspecific. Basically, in fluctuating space principle, space should be divided into functional space and ambiguous space. Functional space accommodates the specific function which has to be carried out. This space should be linked with ambiguous space; a buffer zone in which many alternative activities can be accommodated, to achieve adaptability. This principle allows the planned function to be appropriately serviced, but also allows unplanned, ad-hoc activities to expand out from it as required.

Many issues should be considered in designing an adaptable building; the nature and behavior of users and owners, economical consideration, spatial and functional aspect, structural, technical and even building facade attributes (Nakib, 2010). In order to apply the above adaptable design strategies, certain constructional and operational system must be utilized, such as prefabricated modular construction and adaptive servicing. Prefabrication is one of the route to greater efficiency and faster provision, especially when the building need to change in short period of time. Furthermore, building always needs services to function, and this services need to change according to the building's function. Adaptive servicing talks about changes in services (for example lighting, HVAC, power supply, etc.) as a response to functional changes (Kronenburg, 2007).

\section{CASE STUDY EXPLORATION}

Grüningen Botanical Garden Greenhouse; a greenhouse for subtropical plants located in Grüningen, Switzerland, is taken as the case study explored. The $180 \mathrm{~m}^{2}$ greenhouse is designed by Buehrer Wuest Architekten (Figure 1). The concept of this green house is to be harmonious, open, and integrated with the surrounding environment around the greenhouse, which is the forest (Laylin, 2012). The building design is intended to blend with the surrounding environment, and to maximize the interaction between interior and exterior spaces. Since the site context is a natural forest, the architect decided to take on the shape and structural pattern of the nature as a source of inspiration (Frearson, 2012). The structure consists of four steel tree-like structures; each is five meters tall, which support the glass roof (Laylin, 2012). Every tree trunk is made of twelve steel plate columns arranged radially. Each steel plate column is bent on top, as in arch structure, so that the tree-like structures branch out at the top forming a canopy of the greenhouse.
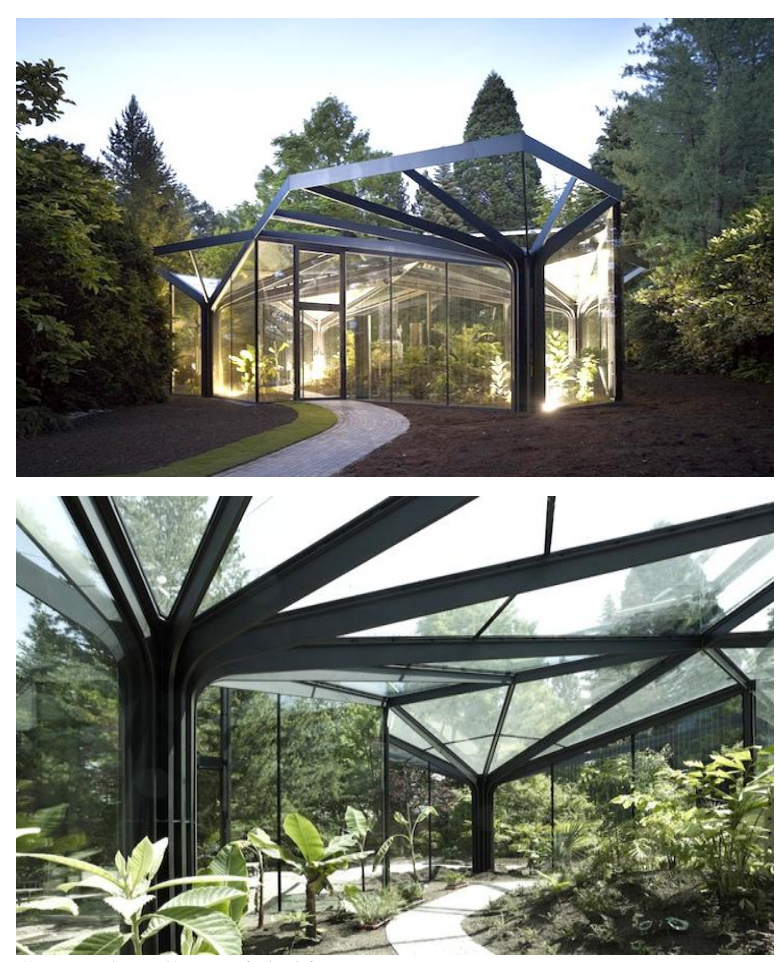

Source: http://www.inhabitat.com

Fig. 1. Greenhouse at Grüningen Botanical Garden

Grüningen Botanical Garden Greenhouse incorporates some sustainable strategies. This project is designed with natural analogy approach by taking the trees in the surrounding forest as the idea to be explored. Taking nature as inspiration is known as an effective way in creating sustainable building, 
because structure in nature has been proven to be efficient, and able to withstand natural forces. Although having some irregularity, the structure of the greenhouse is modular. This project has applied adaptable building principle in the design, which is an open building principle. By implementing four tree structures, a spacious open space is created among the steel columns.

In term of material selection, the use of steel has some advantages. Steel can easily accommodate the desired arch and cantilever form. Moreover, the high strength property of steel helps to minimize the building footprint, and an ideal solution for wide span structure requirement demanded for constructing an open building principle.

The use of glass on the façade of the building blurs the boundary between inside and outside, so that users will feel the sensation of 'open space' that blends with the surrounding forest. Besides, the use of glass provides warmth and illumination for human activities in it (for example, gardening activities, research, observation, etc.), considering the Switzerland cold climate.

\section{DESIGN RESULT}

\section{Design Requirement}

The design process is started by deciding the building function and program as the design requirement.

- Building function and topic

Gallery is taken as the function to be accommodated in the design. This choice was made since gallery usually requires flexible spaces, and it is possible to have various changes along its life span. Thus, gallery is a proper example to be designed with adaptability. Furthermore, the increasing trend of herbal product consumption was selected as the context of the gallery. Herbal product is a cultural heritage which is passed from generation to generation and has the potential to become the distinctive culture of Indonesia. As a result, recently, the number of herbal community has increased significantly. Therefore, herbal gallery is chosen as the building function.

- Architectural programming

Facilities that accommodated in the gallery consists of three main areas; lobby and entrance area, gallery, and multifunction room. Lobby and entrance area is the public area consists of main hall, information center and reception, management office, souvenir shop, and herbal cafe. The gallery includes permanent gallery with flexible arrangement, and non-permanent gallery (called expo area) to host temporary events. Multifunction room is designed as a flexible open space for workshop, seminar, or community activities.

\section{Design Solution}

Based on the design requirements set, the design process is performed. Three different zonings are accommodated in the building; lobby and entrance area, gallery and expo, and the multifunction room, each with its distinct spatial characteristic and structural solution (Figure 2). The lobby and entrance area is designed as a permanent open plan space (except for the management office) with permanent structure. The gallery and expo area is the main

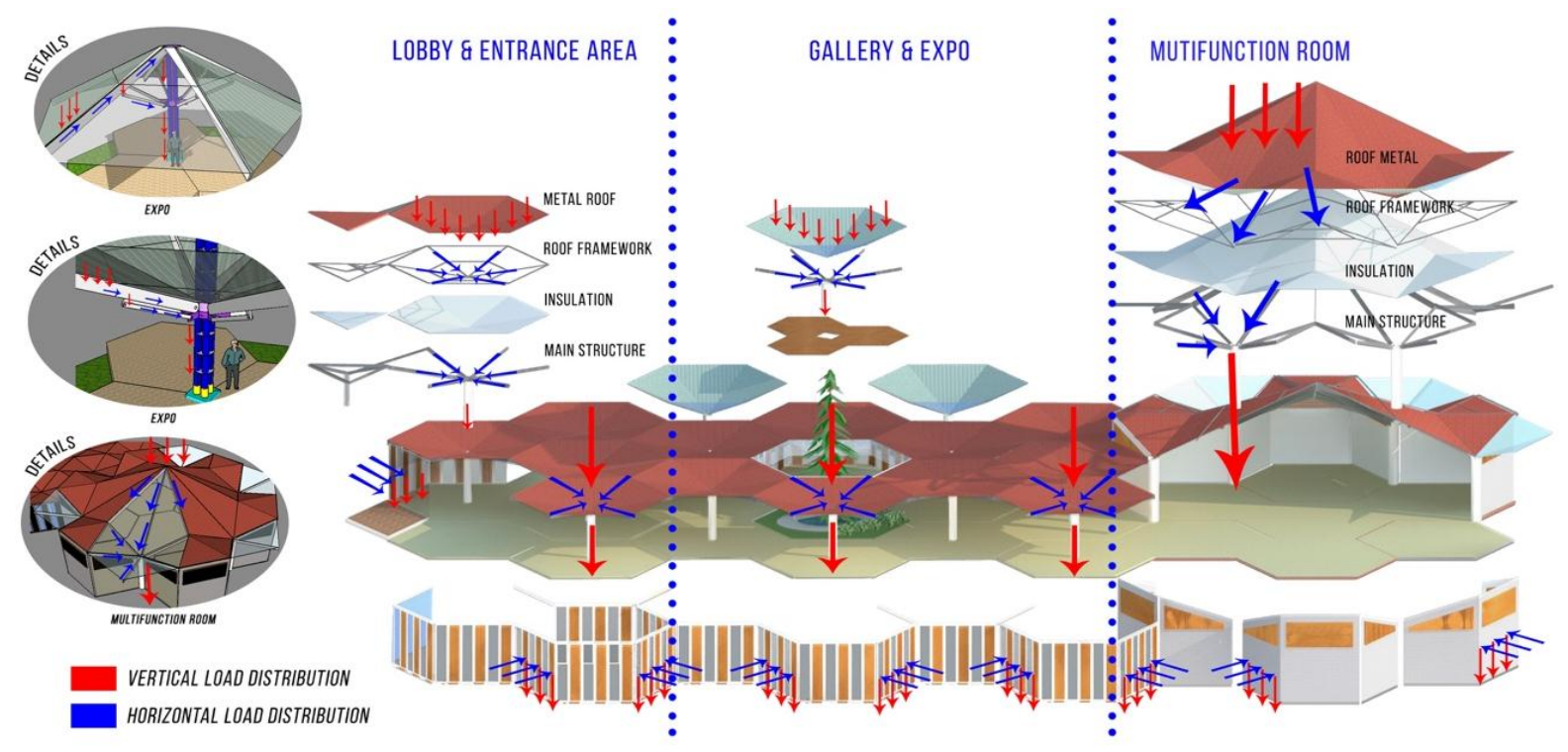

Fig. 2. Final Design with Varied Spatial and Structural Solution 
function implemented adaptable building principles. It has two kinds of space - permanent and temporary spaces, and two types of construction - permanent and knock-down constructions. While the multifunction room is designed as a spacious space with minimum structural components disruption.

The final design resulted incorporates several sustainable strategies in terms of spatial and structural/constructional aspects in order to produce a sustainable adaptable building.

\section{Open building principle}

Adaptability means ability to accommodate various activities in one single space. This concept is appropriate to be implemented in designing the multifunction room. The multifunction room is intended to accommodate various activities, including seminar, workshop, discussion, meeting, or even exhibition. Thus, an open building principle is implemented. Consequently, the room is designed to be an open plan, which means there is no structural components allowed in the middle of the room, to increase spatial flexibility. In here, a wide span structural solution is required, as can be seen in Figure 2.

\section{Fluctuating space}

For the gallery, the choice between permanent and temporary space is required. In permanent gallery, the open building principle is once more applied, to provide flexibility to gallery lay-out. However, an open plan gallery does not have a capacity to be expanded when larger area of gallery is needed. Thus, the gallery is designed as a fluctuating space. The advantage is the space will operate efficiently according to the distinct exhibition event's demand. To do this, the gallery is divided into two main spaces. The first space is the permanent gallery space, which is connected into the second space; the non-permanent gallery space (expo area) as the buffer zone (Figure 3).

\section{Modular Construction}

Modular system is used as the main construction system for both the gallery and the multipurpose room. It offers significant advantages compared to conventional construction system, including shorter construction time, reduced site disruption, financial saving, and flexibility of use. The benefits of modular construction have resulted a widespread acceptance of modular construction as a better solution rather than a conventional construction system. Prefabricated modular structural components makes construction process faster, since it can minimize on-site construction problems and site related delays.

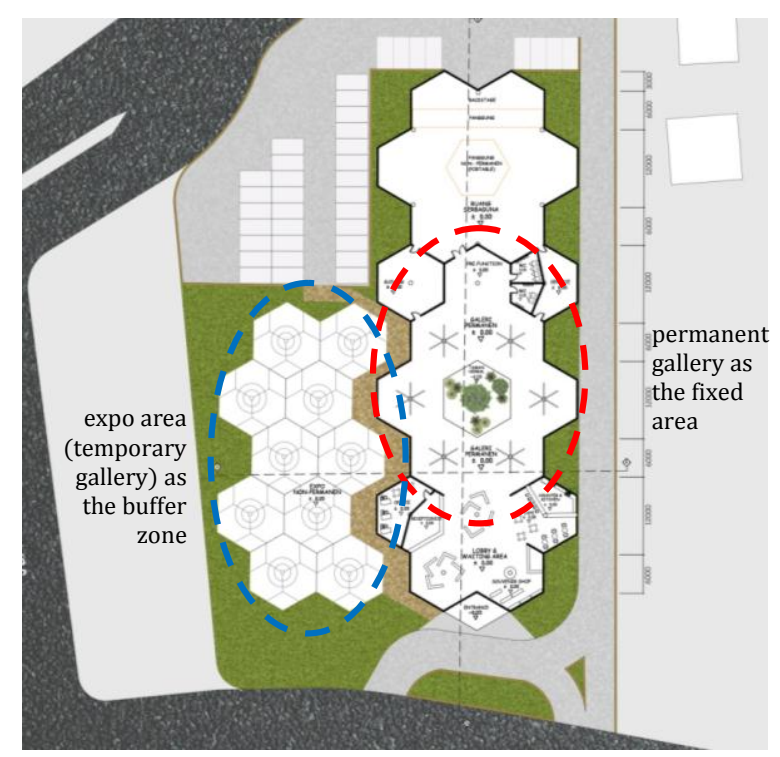

Fig. 3. Building Lay-out Showing the Fixed Area and the Buffer Zone

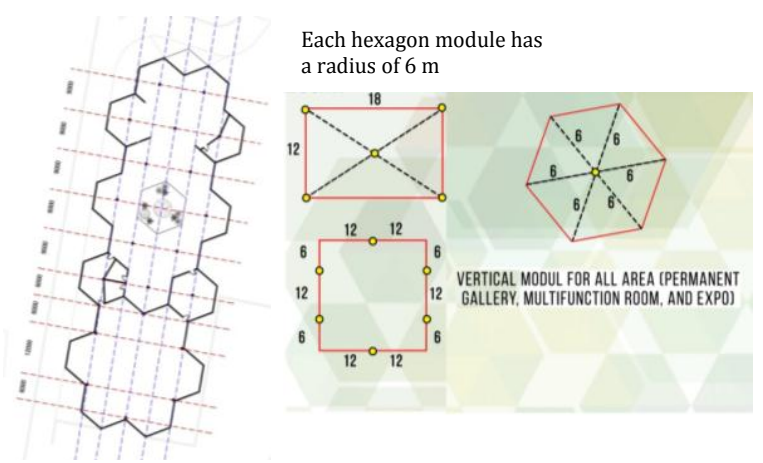

Fig. 4. Modules in the Building

\section{Material Selection}

In selecting the material used in the design, the main criteria applied is durability and product life span. The reason is to support the adaptability of the building, to increase building's life expectancy, and to anticipate high maintenance cost along building occupancy period. The tree-like structure is constructed with steel components. Metal roof is used to cover permanent spaces; including permanent gallery and the multipurpose room, while membrane is used to cover the non-permanent spaces.

\section{Knock-down system}

The temporary gallery/expo area is used occasionally, when the main gallery required more spaces. 
Thus, as the buffer zone in the fluctuating space, it needs high flexibility of existence. For example, a national-scale event requires larger space of gallery, whereas an event with a regional standard may requires fewer space. To accommodate the flexibility, the temporary gallery is designed with a knock-down construction. This means that the temporary gallery's construction is easily dismantled and easily built again, according to variation of functional requirements. When there is no request for additional space, this temporary area can be an outdoor open space area. However, this area can easily be converted into temporary gallery according to the demand.

In applying the knock-down system, taking into consideration the practicality in dismantling and constructing the structure, and the maintenance issue, two forms of the structure is designed. Each module of the structure can switch form from a tree-like shape into an umbrella shape (point 5 and 6 in Figure 5). The tree-like form is used in occupancy phase, when the temporary gallery is in use. If follows the natural analogy of trees such as the case study explored, and considered to produce more aesthetics. The umbrella shape facilitates the maintenance of the structure and to give another alternative appearance.

The main structural components are steel circular hollow section columns. Each four columns are joined as the tree trunk of the structure, while rainwater pipe is located in the middle. The installation system used for these structural columns is knock-down system on concrete pedestals (Figure 5). After the columns are installed, the branch compo- nents and membranes which have been installed into one element will be lifted 2.5 meters high using a hydraulic system (manual or motor-drive hydraulics). Then, two supporting rims for the branch components are locked with pin system. In order to create the form of umbrella, the rims connected to the longer branch members (upper rim) should be lifted until the end of structural column elements. Then, the upper rim should be locked with the same pin and the maintenance can get started. Besides functioning as the main structural element, the columns act as the supporting utilities of rainwater harvesting system. Water and electricity utilities are planted in the concrete floor in order to create an open space for user's activities.

When the temporary gallery is no longer in use, the structure can be dismantled to support the concept of minimizing the building footprint. Hence, the land area can remain in natural condition without permanent pavements. To achieve this condition, the floor covering construction of temporary gallery is also designed with a knock-down system, with easily dismantled wood plastic composite panels (Figure 6).

To maximize flexibility in exhibition/gallery layout, the interior partitions are designed as a knockdown partitions (Figure 7). These partitions for display can be disassembled easily in order to allow various changes of the display. When the partitions are not mounted, the gallery will have wider space. In contrast, the gallery will form smaller display spaces with varied themes when the partitions are installed.

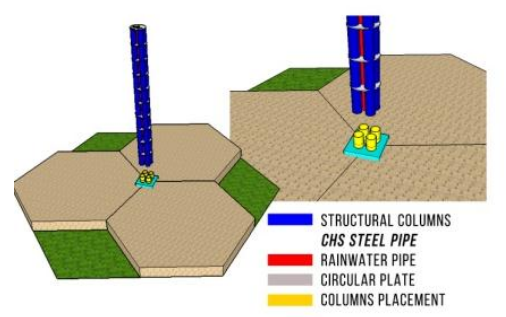

1

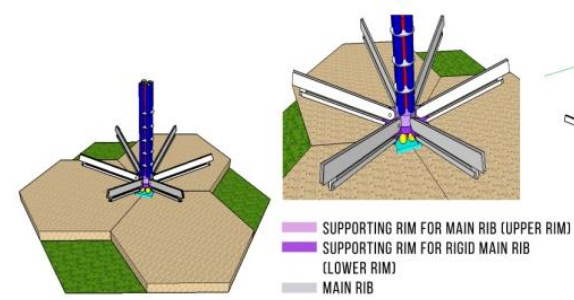

2

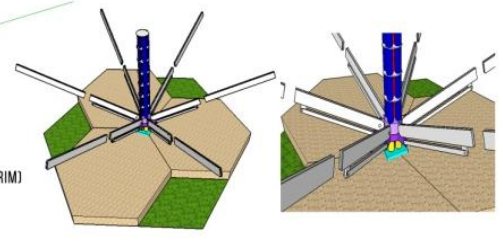

3

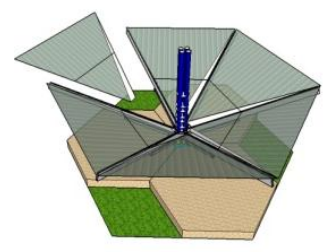

4

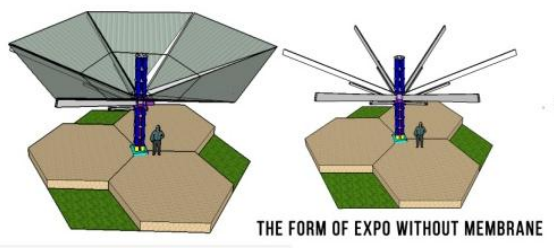

5

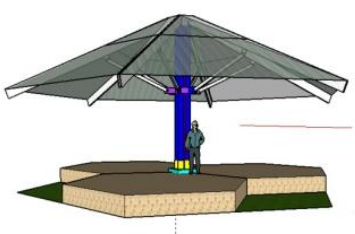

6

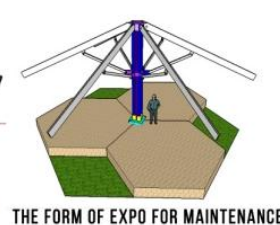

THE FORM OF EXPO FOR MAINTENANC

Fig. 5. The Knock-down Process of Temporary Space's Structure 

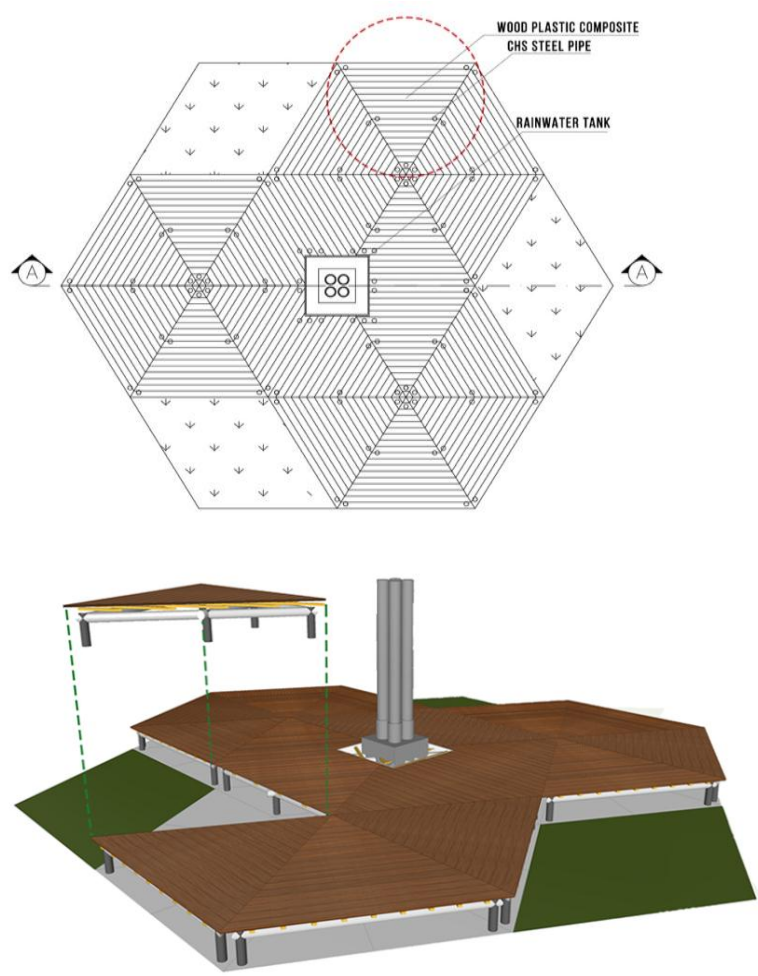

Fig. 6. The Knock-down Floor for the Temporary Space

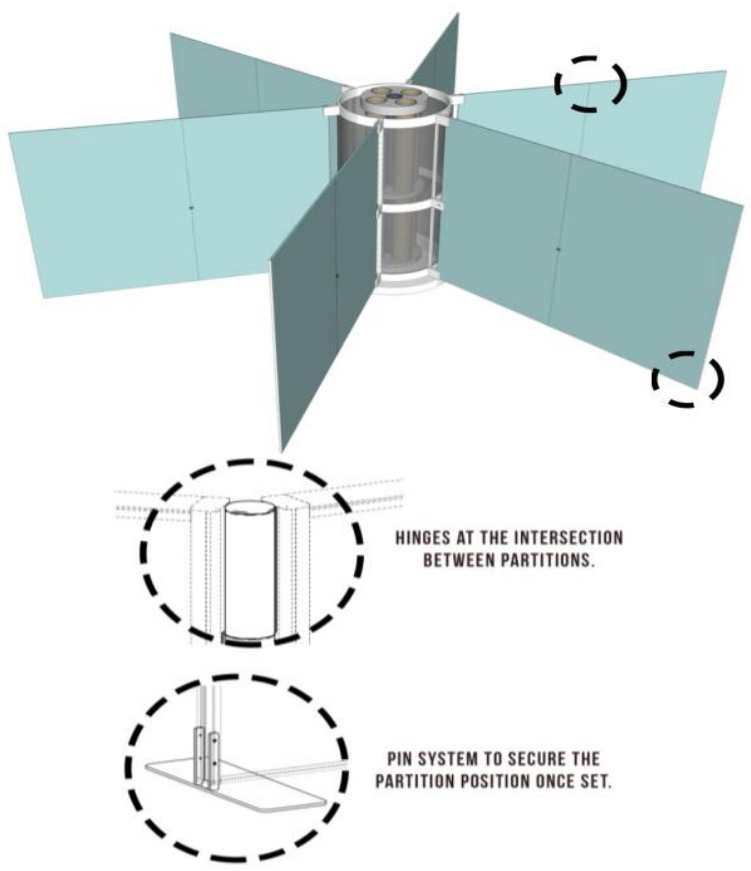

Fig. 7. The Knock-down Interior Displaying Partition

\section{Movable partition}

The outside walls of the permanent gallery and the multipurpose room are made movable, with the aim to provide thermal comfort and visual connection between indoor and outdoor (Figure 8). The outside walls consist of vertical louvre panels and glass. The louvre panels function as a natural ventilation tool, which cools the indoor spaces. Natural ventilation is created between openings in the outside walls and the open courtyard in the middle of the permanent gallery, to allow the stack effect to occur. The perimeter glass and the void above the courtyard allows natural light to penetrate into the gallery. When it is desired, the outside walls can be folded to provide access from the inside to the outside, open connection between the permanent and temporary galleries.

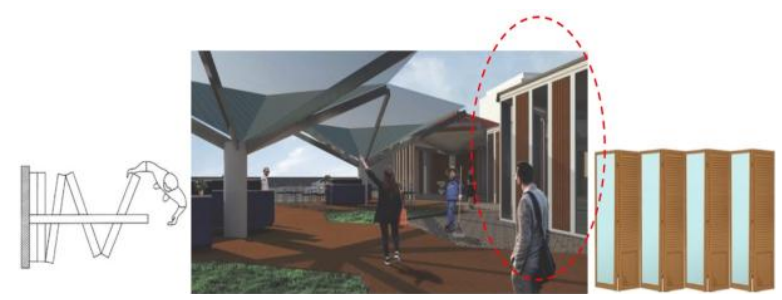

Fig. 8. The Knock-down Partition

\section{DISCUSSION}

Adaptable building which is able to respond and adjust towards the changing needs throughout its life span maximizes the investment value of resources and energy used in its construction process. Designing an adaptable building is essential to support sustainable development to achieve better livings. The process involves deep exploration towards occupants needs and the future changes. Two main issues that should be considered are the spatial and structural/constructional aspects.

This paper is intended to show the benefit of adaptable building concept in achieving a sustainable building, along with the implementation example in a design project which requires complex structural solution and construction details. If the design result is evaluated based on the sustainable architecture criteria, the design result demonstrates several sustainable features:

- Minimizing energy and resources used

By maximizing adaptability, the design result prolongs the life span of the building and minimize the resources and energy used. Without adaptability, building should be demolished sooner due to changes, means more resources and energy is needed to rebuilding.

Application of movable partition which allowing natural ventilation and lighting enhance the indoor air quality inside the building, and minimize the use of active system.

The use of materials with durability and longer product life span reduces resources and energy required for maintenance. 
- Minimizing environmental impact

The knock-down system allows the temporary structure to be dismantled and rebuilt according to the functional demand. In here, the structure is portable and has minimum intervention to the site. Moreover, by utilizing a tree-like structure, the building footprint is minimized.

- Maximizing human comfort

Adaptability is designed to maximize the occupants' comfort under different condition. It was considered as an empathy towards the needs of building occupants and the owner.

The use of movable partition, natural ventilation and lighting ensure a healthy indoor air quality.

The creation of an adaptable building requires certain construction solution and details. In this project, a modular, movable, and knock-down construction is implemented.

\section{ACKNOWLEDGMENT}

The design project presented in this paper is the work of Nikolas, Fida, and Irene to fulfil the assignment of Sustainable Structure and Construction Course.

\section{REFERENCES}

Akmal, I. (2007). Sustainable Construction. PT Gramedia Pustaka Utama, Jakarta.

Architecture Institute of Japan (2005). Architecture for a Sustainable Future. Institute for Building Environment and Energy Conservation, Tokyo.

Dechert, S. (2015). Global Warming or Climate Change? What's The Difference? Retrieved from http://planetsave.com/2015/06/02/globalwarming-or-climate-change-whats-the-difference/
Freason, A. (2012, September 3). Greenhouse at Grüningen Botanical Garden by Buehrer Wuest Architekten. Retrieved from https://www. dezeen.com/2012/09/03/greenhouse-atgruningen-botanical-garden-by-buehrer-wuestarchitekten/

HTA Association (2007). Honeycomb Tube Architecture. Japan, Shinkenchiku-Sha.

Julistiono, E.K. (2011). Sustainable Incremental House with Modular Construction. Proceedings of International Conference "Local Wisdom in Global Era”, Yogyakarta, Indonesia.

Kelly, G., Schmidt III, R., Dainty, A. \& Story, V. (2011a). Improving the design of adaptable buildings through effective feedback in use. Presented paper at the CIB Management and Innovation for a Sustainable Built Environment Conference, Amsterdam, the Netherlands.

Kronenburg, R. (2007). Flexible: Architecture that Responds to Change. Laurence King Publishing Ltd., Great Britain.

Laylin, T. (2012, April 9). Grüningen Botanical Garden Greenhouse Nurtures Bananas and Papayas in Switzerland. Retrieved from http://inhabitat.com/gruningen-botanical-gardengreenhouse-nurtures-bananas-and-papaya-inswitzerland/

Nakib, F. (2010). Toward an Adaptable Architecture: Guidelines to integrate Adaptability in the Building. Proceedings of the CIB 2010 World Congress "Building a Better World", Salford Quays, United Kingdom.

Schmidt III, R., Eguchi, T., Austin, S. \& Gibb, A. (2010b). What is the meaning of adaptability in the building industry? Proceedings of the CIB 16th International Conference on Open and Sustainable Building, Bilbao, Spain.

Smith, P.F. (2007). Sustainability at the Cutting Edge, $2^{\text {nd }}$ edition. Architectural Press, Oxford. 